\title{
An invasive alien Proteaceae lures some, but not all nectar-feeding bird pollinators away from native Proteaceae in South African fynbos
}

\author{
O. Adedoja ${ }^{1}$ (D) L. Erckie ${ }^{2}$, J. S. Boatwright ${ }^{2}$, E. van Wyk ${ }^{3,4}$ \& S. Geerts ${ }^{5}$ \\ 1 Department of Conservation and Marine Sciences, Cape Peninsula University of Technology, Cape Town, South Africa \\ 2 Department of Biodiversity and Conservation Biology, University of the Western Cape, Cape Town, South Africa \\ 3 South African National Biodiversity Institute, Cape Town, South Africa \\ 4 Institute for Coastal and Marine Research, Nelson Mandela University, Gqeberha, South Africa \\ 5 Department of Conservation and Marine Sciences, Center for Invasion Biology, Cape Peninsula University of Technology, Cape Town, South Africa
}

\section{Keywords}

nectar; pollen limitation; seed production;

self-compatibility; sugarbirds; sunbirds.

\section{Correspondence}

O. Adedoja, Department of Conservation and Marine Sciences, Cape Peninsula University of Technology, P.O. Box 652, Cape Town 8000, South Africa.

E-mail: adedojaopeyemiadebayo@gmail.com

\section{Editor}

A. Dafni

Received: 24 August 2020; Accepted: 27 May 2021

doi:10.1111/plb.13300

\section{ABSTRACT}

- Invasive alien plants often influence pollinator visitation to native plants when sharing pollinator guilds. It is of conservation concern when the invasive alien plant is characterized by floral resources that attract pollinators, thereby reducing the reproductive success of native species. This is well studied for insects, but whether the same is true for bird pollinators is largely unknown. We address this by considering the impact of an invasive alien plant (Banksia speciosa) on visitation rates of nectar-feeding bird pollinators to native Protea compacta in the Cape Floristic Region of South Africa.

- We determined bird pollinator visitation rate to B. speciosa and P. compacta over $21 \mathrm{~h}$ of observation at three sites. We also quantified how visitation rate influenced reproductive success of both study species through different breeding experiments.

- Sugarbird visitation to $P$. compacta was significantly lower in the presence of $B$. speciosa, while there was no effect for sunbirds as they mostly avoided B. speciosa. Protea compacta had higher nectar volumes and sucrose per flower than B. speciosa. Sucrose per hectare was higher in all $P$. compacta plots compared to B. speciosa. Neither study species is pollen limited and they are self-compatible to some extent. But pollinator visitation enhanced seed production in both species.

- We show here that the invasive alien B. speciosa flowers attract sugarbirds - but not sunbirds - away from native P. compacta. The long-term effect of reduced pollinator visitation may reduce the fitness of $P$. compacta, but the long-term demographic impact is unknown and would require further study.

\section{INTRODUCTION}

Competition for shared resources, including pollinators, is one of the most common forms of interactions between native and invasive plant species (Bjerknes et al., 2007), especially when floral traits overlap (Gibson et al., 2012). Often, invasive alien plants are characterized by showy floral displays and copious rewards that attract pollinators and reduce visitation to native flowering plants, especially when they act as magnet species (Chittka \& Schürkens, 2001; Traveset \& Richardson, 2014). Conversely, invasive alien plants can also increase overall attraction and thereby facilitate the visitation of pollinators to native species within the invaded area (Morales \& Traveset, 2009). Overall, fitness may be influenced by the degree of competition between native and invasive flowering plants for pollinators (Van Kleunen et al., 2010) and this may aid the invasion potential of alien plants in the introduced range (Pimentel et al., 2005; Vilà et al., 2011).

Globally, approximately $87.5 \%$ of flowering plants depend on animal pollination for seed production (Ollerton et al., 2011). Animal pollinators also enhance seed production in pollen-limited species, especially in areas with high plant species diversity (Vamosi et al., 2006). For invasive alien plant species, an increase in seed production due to high visitation by native pollinators will enhance invasiveness in the novel range (Geerts \& Pauw, 2009; Razanajatovo et al., 2016). Most pollination studies that have addressed competition between native and invasive alien plants have adopted experimental approaches, such as using potted plants to study these interactions (see e.g. Kandori et al., 2009; Flanagan et al., 2010) and less often test this in a natural setting (but see Vilà et al., 2009; Gibson et al., 2012). The grand-scale transplant experiments provided by the introduction of alien species can teach us much about competition for pollinators. This is well studied for insect pollinators (see Jakobsson et al., 2009; Parra-Tabla et al., 2019), but not so for bird pollinators (but see Richardson et al., 2000; Ollerton et al., 2012). Such an opportunity is presented when an alien bird-pollinated plant species is introduced and invades parts of the world with native bird pollinators.

In the Cape Floristic Region (CFR) of South Africa, bird pollinators are crucial for the maintenance of the Cape's floral 
diversity by pollinating about $4 \%$ of the flora, yet it appears that pollinators, and in particular nectar-feeding birds, are threatened (Kearns et al., 1998). The bird-pollinated plant and nectar-feeding bird mutualism is threatened by frequent fires (Van Wilgen, 2009; Geerts et al., 2012), roads (Geerts \& Pauw, 2011a), beekeeping (Geerts \& Pauw, 2011b), habitat fragmentation (Geerts \& Pauw, 2009; Geerts, 2016), climate change (Mackay et al., 2017) and potentially invasive species (Mangachena \& Geerts, 2017). The dominant overstorey species in fynbos are Proteaceae, of which approximately $25 \%$ depend on nectar-feeding birds for pollination. However, this highly specialized form of interaction is rather simple as only four species of nectar-feeding bird act as important pollinators (Geerts, 2011). At small spatial scales, Proteaceae nectar, rather than vegetation structure, determines the distribution and abundance of the nectar-feeding bird community (Geerts et al., 2020). There is some evidence to suggest that additional nectar in the landscape benefits the nectar-feeding bird community (see Le Roux et al., 2010; Schmid et al., 2015; Gray and Heezik 2016; Le Roux et al., 2020) but whether this indeed increases the number of nectar-feeding birds has not been quantified. Invasive alien species may alter nectar quantity at landscape scale through addition of nectar (Le Roux et al., 2010, 2020) or even through nectar replacement that may occur when invasive species spread rapidly and outcompete native flowering plants. This is important when considering the possible pathways through which invasive alien flowering plants alter the quantity and properties of floral rewards at landscape scale, influencing the visitation rates as well as the community of pollinators in the invaded areas.

Here we investigate whether the addition or replacement of nectar by the alien invasive Banksia speciosa $\mathrm{R}$. Br. influences the nectar-feeding bird community and their dependant native plants in the CFR. We selected the invasive Banksia speciosa and the native Protea compacta R. Br. since they co-occur, flower simultaneously and are both bird-pollinated (Paton \& Turner, 1985; Collins \& Rebelo, 1987; Steenhuisen \& Johnson, 2012) and visited by Cape sugarbirds and sunbirds (Mostert et al., 1980; Moodley et al., 2016). Approximately 14 species of the genus Banksia were introduced from Australia to South Africa for floriculture (Moodley et al., 2013). Two of these, $B$. ericifolia L.f. and $B$. integrifolia Meisn., have become invasive, while species such as B. speciosa have become naturalized in some areas of the CFR based on climate suitability, propagule pressure and ability of this species to adapt to land-use and other anthropogenic disturbances in this region (Honig et al., 1992; Geerts et al., 2013; Moodley et al., 2014).

Because of the co-occurrence and overlapping flowering period of B. speciosa with native P. compacta, as well as the production of copious amounts of nectar by B. speciosa (George 1999; Moodley et al., 2016), which often attracts nectar-feeding birds, we hypothesize that $B$. speciosa will compete with the native, co-flowering $P$. compacta for nectar-feeding bird pollinators (Catford et al., 2009; Traveset \& Richardson, 2014), and by doing so reduce seed set in $P$. compacta. Alternatively, B. speciosa can facilitate the overall visitation of nectar-feeding bird pollinators to $P$. compacta (Morales \& Traveset, 2009). We thus ask the following questions: (i) does the addition of B. speciosa to the landscape change nectar-feeding bird communities; (ii) does the invasive $B$. speciosa influence nectar-feeding bird visitation rates to the native $P$. compacta; and (iii) does the altered visitation rate to native $P$. compacta, if any, reduce seed set of $P$. compacta?

\section{MATERIAL AND METHODS}

\section{Study area}

Study sites were located at Soetanysberg (34 $44^{\prime} 667$ S, $\left.19^{\circ} 52^{\prime} 931 \mathrm{E}\right)$ and Bergplaas (3443'585 S, 1952'488 E) in the Agulhas National Park, Western Cape Province, South Africa. The area experiences a Mediterranean-type climate characterized by cold wet winters and warm dry summers. It receives mean annual rainfall of $452 \mathrm{~mm}$. The mean temperature ranges between $13.5^{\circ} \mathrm{C}$ and $20.6{ }^{\circ} \mathrm{C}$ for the cool and warm months, respectively (Richards et al., 1995).

Banksia speciosa is a perennial woody shrub that grows up to 8-m tall (George, 1981; Richardson et al., 1990). The cream to pale yellow hermaphroditic and protandrous flowers are grouped into a long inflorescence of 4-12 cm (George, 1981; Fig. 1A). The selected native species, Protea compacta, is a nonsprouting serotinous shrub of up to $3.5-\mathrm{m}$ tall that is endemic to the fynbos (Rourke, 1982; Rebelo, 2001). The pink and white flowers of $P$. compacta are grouped into large inflorescences.

Field observations were conducted at three sites with similar veld age during July and August 2016, which are the peak flowering months for B. speciosa and P. compacta. Native vegetation invaded by a 2-ha stand of B. speciosa (the Banksia site, Fig. 1A) and an adjacent 1.5-ha monospecific stand of native $P$. compacta (Fig. 1B), termed the Protea experimental site, were used as study sites. A P. compacta stand of 1.8 ha was located $2.6 \mathrm{~km}$ away and used as a control site. Protea compacta was the most abundant native bird-pollinated flowering plant species at both the experimental and control sites. However, in the Banksia site, $B$. speciosa was the dominant bird-pollinated species. The abundance of $P$. compacta was similar between the experimental and control site (with 32 and 33 plants per $25 \mathrm{~m}^{2}$, respectively), while B. speciosa had fewer stems per area (24 stems per $25 \mathrm{~m}^{2}$ ), although the plants were larger.

\section{Nectar-feeding bird abundance}

To determine nectar-feeding bird abundance and richness in invaded and uninvaded sites, a 10 -min point count method was used (Bibby et al., 2000). Due to small stand size at both sites, only one fixed point was established within each stand. Bird observations were conducted between 7:00-12:00 $\mathrm{h}$ - when nectar volume was highest - on good weather days without rain and little or no wind. Birds are more active in the morning when nectar volume is highest (Kalinganire et al. 2001) and flower visitation tends to decrease after midday (Sun et al., 2017). Sites were sampled multiple times per day in an alternating manner for 8 days, spread out over the peak flowering period. The species and number of individual nectar-feeding birds seen within a $40-\mathrm{m}$ radius from the observer were recorded. Bird observations were carried out by two observers per site with Nikon $8 \times 42$ binoculars, and we merged data collected by the two observers for statistical analysis.

\section{Nectar-feeding bird pollination rates}

To determine nectar-feeding bird visitation rates, the number of bird visits to 20 focal inflorescences was recorded for $30 \mathrm{~min}$ 
Fig. 1. (A) Density of B. speciosa across the Banksia site, (B) homogenous distribution of $P$. compacta across the Protea control site, (C) Sugarbird feeding on nectar from an alien $B$. speciosa inflorescence, (D) male Cape sugarbird feeding on $P$. compacta nectar. A-Ernita van Wyk; B, C-Sjirk Geerts D- Laimi Erckie.
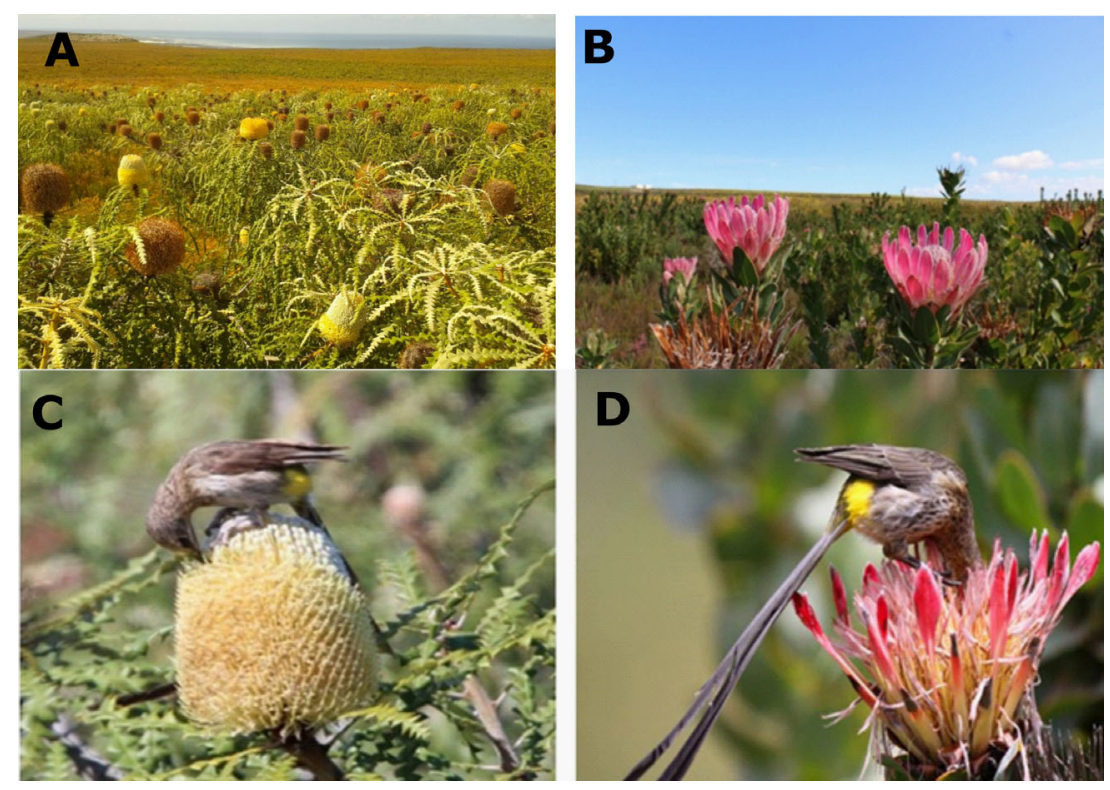

at each site. Birds were only considered as potential pollinators once they made contact with the flower's receptive part. Sites were observed at least twice per day and were sampled in an alternating manner to eliminate any temporal bias in observations. Each site was sampled for a total of $7 \mathrm{~h}$, resulting in a total of $21 \mathrm{~h}$ of observations conducted during the winter season, which is the peak flowering period of our two study species. Total bird visitation observation was low, but many flowers observed during this period had 20 inflorescences $(>$ 100 flowers each) that were observed simultaneously. Unlike other pollination studies, nectar-feeding bird abundance was also recorded for $21 \mathrm{~h}$. Also, with observations spread out over multiple weeks, and at least $40 \mathrm{~h}$ spent on nectar measurements and hand-pollination of flowers in these populations, during which anecdotal bird observations was conducted, the sampling period was sufficient.

\section{Nectar properties and availability}

To determine the quantity of floral nectar rewards available to nectar-feeding birds, a representative $5 \times 5$-m plot was established at each site. The number of open inflorescences in each plot was counted. In Protea inflorescences, the outer ring of the flowers matures first, followed by the inner rows of the flower. We therefore measured nectar volume and concentration (from ten inflorescences from different plants) in open flowers $(n=14)$ across the middle of the inflorescence, totalling 140 flowers per study site, thereby effectively sampling flowers across all ages (Geerts et al., 2020). This controls for differences in nectar volume between flowers of varying age in an inflorescence. Inflorescences were collected early in the morning from study sites and nectar was extracted in the laboratory using $5 \mu \mathrm{l}$ or $40 \mu \mathrm{l}$ microcapillary tubes. Nectar sugar concentration was determined with a $0-50 \%$ handheld refractometer. All nectar measurements were transformed to milligrams (mg) of nectar sugar (sucrose equivalents). The standing crop of nectar, which provides an estimate of the nectar available to pollinators at a given time, was measured early morning when the birds are most active (Kearns \& Inouye, 1993). The average nectar volume and concentration per flower was then calculated and multiplied by the total number of flowers in the inflorescence then multiplied by the total number of inflorescences per $5 \times 5-\mathrm{m}$ plot and scaled up to nectar $(\mathrm{mg}$ nectar sugar) per hectare.

\section{Breeding system experiments}

To determine whether $P$. compacta is pollen-limited when nectar-feeding bird pollinators are lured away by B. speciosa, exclusion of pollinators and pollen addition experiments were conducted. Between 15 and 30 plants of each species were randomly selected in the Banksia site, Protea experimental site and Protea control site, and randomly allocated to one of the three treatments: (a) one inflorescence still in bud phase was bagged with fine-mesh nylon bags to exclude all pollinators, (b) another inflorescence, also in bud phase was tagged, and once flowers opened, hand-pollinated with pollen from multiple donors (rubbing pollen onto the receptive stigma with a $25-\mathrm{mm}$ paint brush), (c) one inflorescence was tagged as a control and left uncovered to allow access by pollinators. Similar-sized and -aged inflorescences were selected to ensure consistent maturity across inflorescences for the different treatments. Infructescences were harvested 6 months after flowering to determine seed production. Follicles of B. speciosa were opened by heating infructescences in an oven for between 2-30 days at $120^{\circ} \mathrm{C}$ and seeds counted. Seeds of $P$. compacta were counted immediately upon harvesting their infructescences.

\section{Data analysis}

To understand how floral visits to the invasive $B$. speciosa and native $P$. compacta are affected by differences among taxonomic groups as well as the general ecology of the four nectarfeeding bird species recorded in this study, we separated the analysis into two broad groups using data from visitation rates 
of sugarbirds as well as visitation rates of the three sunbird species.

We pooled visitation and abundance data for all sampling periods that occurred on the same day for each group. Visitation frequency was converted to visitation rate per inflorescence per hour and this was used to explore the pattern of visitation among bird species across study sites. The ShapiroWilk's test was performed on all data to test for normality. We conducted non-parametric Kruskall-Wallis tests to determine differences in nectar-feeding bird abundance, flower visitation rate per inflorescence per hour, nectar volume and sucrose per flower among study sites. A Dunn's test was used to determine significance among paired study sites.

To determine differences in number of seeds produced per plant species across study sites for $B$. speciosa and $P$. compacta, we applied a generalized linear model, specifying quasi-Poisson error to account for overdispersion of data. All statistical tests were conducted using R (R Core Development Team, 2017).

\section{RESULTS}

\section{Nectar-feeding bird abundance}

A total of 465 bird visitations from four nectar-feeding bird species, the Cape sugarbird (Promerops cafer Linnaeus 1758), Orange-breasted sunbird (Anthobaphes violacea Linnaeus 1766), Southern double-collared sunbird (Cinnyris chalybeus Linnaeus 1766) and Malachite sunbird (Nectarinia famosa Linnaeus 1766), were recorded. Among study sites, Cape sugarbird were significantly more abundant in the Banksia site compared to other sites (Kruskal-Wallis chi-square $=13.90$, $\mathrm{df}=2, P=0.001$; Fig. 2A). There was no significant difference in Cape sugarbird abundance between Protea control and Protea experimental sites. Unlike sugarbirds, sunbirds were significantly less abundant in the Banksia site compared to the Protea sites (Kruskal-Wallis chi-square $=9.74, \quad \mathrm{df}=2$, $P=0.008$; Fig. 2A). There was no significant difference in sunbird abundance between Protea control and Protea experimental sites.

\section{Nectar-feeding bird pollination rates}

Banksia speciosa received three times as many visits by nectarfeeding birds per inflorescence per hour as $P$. compacta. Visitation rate of sugarbirds was significantly higher in the Banksia site, followed by Protea control site, and lowest in the Protea experimental site (Kruskal-Wallis chi-square $=19.35, \mathrm{df}=2$, $P<0.001$; Fig. 2B). Among study sites, visitation rate of sunbirds was significantly lower to B. speciosa compared to P. compacta sites (Kruskal-Wallis chi-square $=11.99, \quad \mathrm{df}=2$, $P=0.003$; Fig. $2 \mathrm{~B}$ ). There was no significant difference in visitation rate of sunbirds to $P$. compacta in Protea control and Protea experimental sites.

\section{Nectar content}

Banksia speciosa nectar volume per flower (mean $\pm \mathrm{SE}=$ $3.3 \pm 0.13,0.5-6.0 \mu \mathrm{l})$ was significantly lower than that of $P$. compacta (Kruskal-Wallis chi-square $=24.897, \quad P<0.05$, $\mathrm{df}=2,24.26 \pm 0.62,5-58 \mu \mathrm{l})$. Nectar volume per inflorescence was also significantly lower for B. speciosa $(53.55 \pm 11.01$, 11.5-141.5 $\mu \mathrm{l}$ ) compared to $P$. compacta (Kruskal-Wallis chisquare $=22.986, \quad P<0.05,366.25 \pm 28.1,198-445 \mu \mathrm{l})$. Total amount of sucrose per hectare was $80.64 \mathrm{~g}, 222.73 \mathrm{~g}$ and $934.94 \mathrm{~g}$ in Banksia, Protea experimental and Protea control sites, respectively. Sucrose per flower was significantly lower in B. speciosa $(0.61 \pm 0.03,0.08-1.88 \mathrm{mg})$ compared with $P$. compacta (Kruskal-Wallis chi-square $=23.205, P<0.001, \mathrm{df}=2$, $5.23 \pm 0.21,0.82-16.27 \mathrm{mg}$ ).

\section{Breeding system}

Pollen addition by hand did not significantly increase seed production of $B$. speciosa or $P$. compacta among all study sites $(\mathrm{F}=2.55, P=0.092, \mathrm{df}=2)$, showing that neither plant species was pollen-limited. The number of seeds produced by $B$. speciosa and $P$. compacta was significantly lower in pollinatorexcluded flowers (Banksia $\mathrm{F}=8.19, \mathrm{df}=2, P=0.0007$ and Protea control sites $\mathrm{F}=11.63, \mathrm{df}=2, P<0.0001$; Fig. 3 ). In contrast, there was no significant difference in the number of seeds produced among treatments in the Protea experimental site ( $\mathrm{F}=1.55, \mathrm{df}=2, P=0.22$; Fig. 3 ). Overall, there was no significant difference in natural seed set between Protea control and experimental sites $(t=1.5, P=0.14)$.

\section{DISCUSSION}

The alien invasive Banksia speciosa attracted sugarbirds away from native species, yielding a lower visitation rate of sugarbirds to native $P$. compacta flowers. This is important when considering the impact of invasive $B$. speciosa on the pollination of native flowering plant species that share similar pollinators. However, we did not find a decline in seed production in $P$. compacta occurring in close proximity to $B$. speciosa. This may be because of the higher visitation rate of sunbirds in the Protea site compared to the Banksia site. Sunbirds are also effective pollinators of $P$. compacta and they may supplement the reproduction of $P$. compacta when sugarbirds are scarce. Also, a reduction in pollinator visitation does not always result in a parallel decline in seed set (Lundgren et al., 2013), especially when flowering plants are adapted to different pollination modes, such as autogamy whereby pollination is achieved even when pollinator visitation rate is low.

Floral rewards, especially nectar, play a critical role in attracting pollinators to ensure effective pollination (Carr et al., 2015; Prasifka et al., 2018). Although the amount of nectar produced per flower is important to support the energy requirements of birds, more importantly, the quantity of nectar per hectare - which largely depends on flower abundance - is critical for the overall attraction and maintenance of birds at landscape scale (Nottebrock et al., 2017). Despite the similar density of $P$. compacta in the experimental and control site, we observed a large difference in the total amount of sucrose per hectare between the two sites, with higher sucrose per nectar sample recorded in the control site. Since dense stands of B. speciosa form thickets, this may reduce the access of $P$. compacta to sunlight, which is critical for nectar production (Nocentini et al., 2013). Also B. speciosa may compete with native $P$. compacta for other abiotic factors, such as soil nutrients, space, water and other 


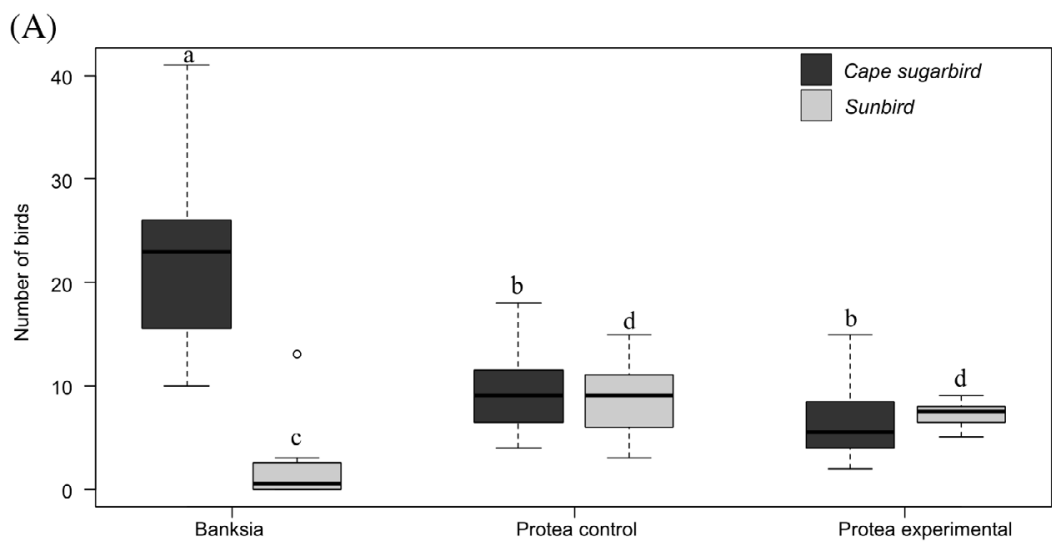

Fig. 2. Differences in (A) abundance and (B) visitation rate per inflorescence per hour of sugarbirds and sunbirds to $B$. speciosa and $P$. compacta across study sites. Boxplots display the median with a solid line, 25th and 75th percentiles in the lower and upper boxes, respectively, data range is indicated by the whiskers. Different letters indicate significant differences among study sites at $P<0.05$.

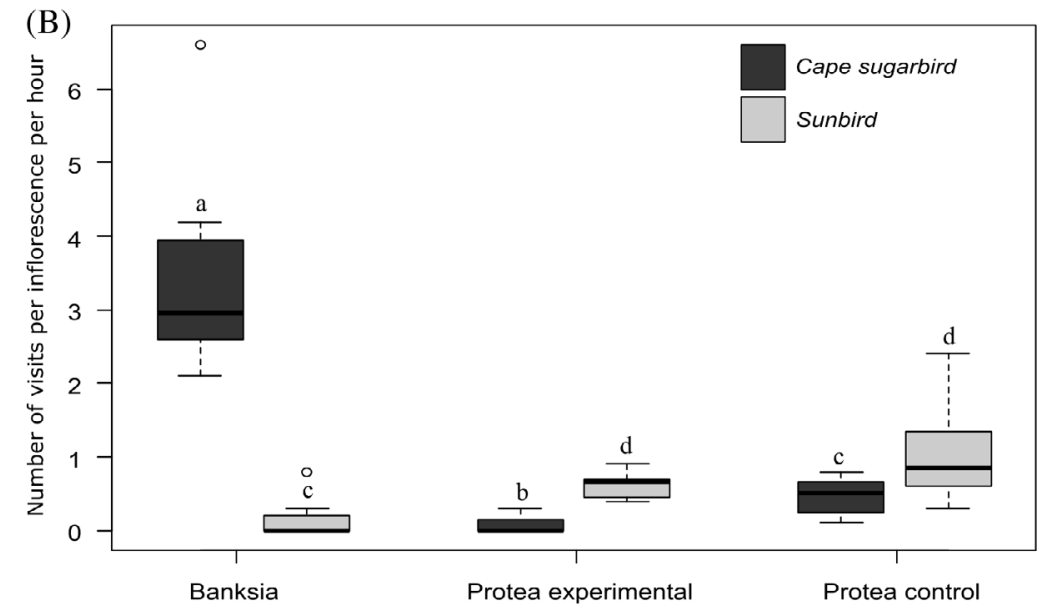

factors that may influence the fitness of $P$. compacta in the experimental sites. However, the low nectar per hectare recorded for $B$. speciosa did not explain the high abundance and visitation rates of sugarbirds. This also contrasts with results of Geerts et al. (2013), where high nectar volume in $B$. ericifolia doubled the nectar available to birds in the study area. While this could be because of high foraging activity of sugarbirds, measuring flowers in the early morning - as was done in this study - should have circumvented this. Also, measuring nectar in ten inflorescences from different plants and ensuring that flowers sampled $(\mathrm{n}=14)$ per inflorescence were representative - by sampling across the inflorescence - reduces the bias of varying nectar volume among inflorescences and plants in both species. Therefore, what drives the high visitation rate of sugarbirds to $B$. speciosa remains to be determined.

The Cape sugarbirds are relatively larger in body size compared to sunbirds, and they also outcompete sunbirds during visits to flowering plants for nectar (Schmid et al., 2016). The difference in the morphology of these two bird species may explain why the abundance and visitation rates of sunbirds were low in Banksia and Protea experimental sites, where sugarbird abundance and visitation rates were higher compared to the control site. Cape sugarbirds were highly attracted to invasive B. speciosa in this study, and this may aid in the integration of this invasive species into the plant-bird interactions of the CFR (Maruyama et al., 2016). Species-specific floral traits of $B$. speciosa may mediate the high visitation rate of sugarbirds in this study. Unlike the relatively small and slender $P$. compacta, $B$. speciosa is characterized by a sturdy stem suitable to support the relatively large sugarbirds, especially during the breeding period when males display to attract females. Also, insects are often attracted to B. speciosa (Moodley et al., 2016), which in turn could attract sugarbirds; particularly during the breeding season - as in this study -, when insects supplement the diet and are an important source of protein for female sugarbirds (Mostert et al., 1980). In addition, stands of B. speciosa form denser thickets, which could be important in protecting sugarbirds against predators and harsh weather (Burger et al., 1976). Thickets may also provide more nesting sites for sugarbirds and may further support the preference of sugarbirds for $B$. speciosa.

Floral traits are key influencers of plant-plant interactions, predicting the impact of invasive alien plants on native species, especially when they compete for similar resources such as pollinators (Gibson et al., 2013). This is well researched 


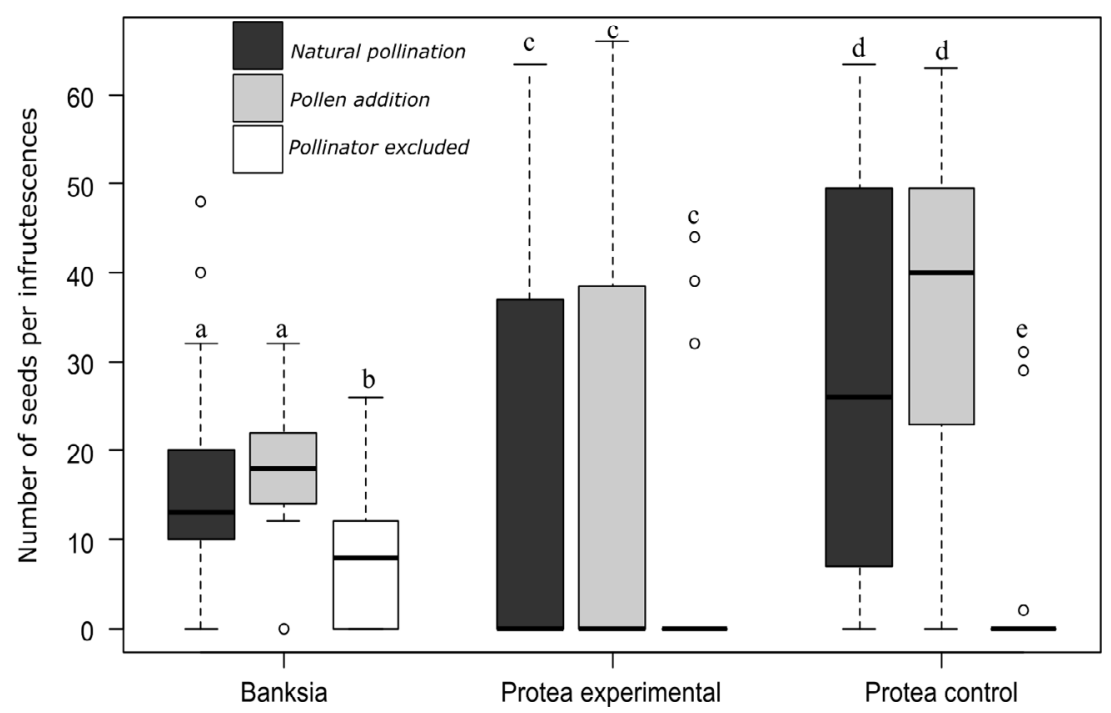

Fig. 3. Number of seeds per infructescence for the different breeding system experiments. Boxplots display the median with a solid line, 25th and 75th percentiles in the lower and upper boxes, respectively, data range is indicated by the whiskers. Different letters indicate significant differences among treatments per species per study site at $P<0.05$. for insect-pollinated species (Moroń et al., 2009; Gibson et al., 2012) where alien plants alter ecosystem functioning due to reduced fitness of native species in competition. While this study is one of the few studies that has assessed how invasive alien plants influence pollination of native bird-pollinated species, there is an urgent need for a comprehensive assessment addressing the influence of invasive alien species on nectar-feeding birds. The effects of invasive alien plants on the reproductive success of native species through competition for pollinators are often densitydependent (Muñoz \& Cavieres 2008). With an increasing number of nectar-rich invasive alien species in the CFR attracting pollinators away from the highly pollinator reliant Proteaceae, ecosystem functions in the CFR may become threatened.

Banksia speciosa is self-compatible and capable of producing seeds through autogamy, as recorded in this study. The ability to reproduce without the intervention of animal pollinators aids in the success of alien species such as B. speciosa in its introduced range (Rambuda \& Johnson, 2004; Pyšek et al., 2011). Although B. speciosa is self-compatible, this study shows the importance of pollinators in enhancing seed production. This supports other studies that have underscored the role of pollinators in increasing seed production of invasive plant species and subsequently enhancing invasiveness (Geerts \& Pauw, 2009; Rodger et al., 2010; Moodley et al. 2016). Hand pollination did not increase seed production of B. speciosa or P. compacta in this study, showing that both species are not pollenlimited. Although, pollen addition slightly increased seed set in P. compacta in the Protea experimental site, this was not significant. The lack of an increase in seed set with hand pollination may be attributed to the typical low seed set in Proteaceae or to the large number of flowers per inflorescence that open sequentially over a long period, limiting the effectiveness of hand pollination.

In conclusion, our results support our hypothesis that invasive $B$. speciosa stands attract sugarbirds away from native $P$. compacta stands; however, this did not reduce the seed set of the native $P$. compacta. The effect of an invasive alien plant in attracting sugarbirds away from native species may be masked by the presence of sunbirds, which enhance the reproduction and fitness of native $P$. compacta when sugarbird numbers are reduced. Although the overall abundance of sugarbirds is approximately three times that of sunbirds in this study, sunbirds maintained their preference for the native species, especially in the absence of the competitive sugarbirds. This is of significance when considering a reliable pollinator for the persistence of native species in an invaded ecosystem. However, understanding the extent to which invasive B. speciosa mediates pollinator visitation to $P$. compacta in the long term requires further investigation. Despite only considering a small pollinator community and having relatively low sampling intensity, this study is one of very few that have assessed the influence of an invasive bird-pollinated plant species on native plant seed production and interactions with native bird pollinators. Since invasive alien plant species are becoming more established in natural ecosystem, competing for resources and integrating into native ecological interactions (Olesen et al., 2002; Morales \& Aizen, 2006; Vilà et al., 2009), future studies should assess the role of floral traits and degree of biotic and abiotic resource overlap between invasive and native flowering plant species and how these influence interactions between native plants and nectar-feeding birds. Furthermore, the demographic consequences of a long-term reduction in pollinator visitation should also be considered.

\section{ACKNOWLEDGEMENTS}

The South African Department of Forestry, Fisheries and the Environment (DFFtE) are thanked for funding, noting that this publication does not necessarily represent the views or opinions of DFFtE or its employees. We gratefully acknowledge field assistance from Stanley Engel's teams from the Expanded Public Works Programme (Agulhas). We thank SANParks Research Centre for the research permit and the Agulhas National Parks staff for support throughout. 


\section{REFERENCES}

Bibby C.J., Burgess N.D., Hill D.A., Mustoe S. (2000) Bird census techniques. Elsevier, Amsterdam, the Netherlands.

Bjerknes A.L., Totland Ø., Hegland S.J., Nielsen A. (2007) Do alien plant invasions really affect pollination success in native plant species? Biological Conservation, 138, 1-12.

Burger A.E., Siegfried W.R., Frost P.G.H. (1976) Nestsite selection in the Cape sugarbird. African Zoology, 11, 127-158.

Carr D.E., Haber A.I., LeCroy K.A., Lee D.A.E., Link R.I. (2015) Variation in reward quality and pollinator attraction: the consumer does not always get it right. AoB Plants, 7, plv034. https://doi.org/10.1093/ aobpla/plv034.

Catford J.A., Jansson R., Nilsson C. (2009) Reducing redundancy in invasion ecology by integrating hypotheses into a single theoretical framework. Diversity and Distribution, 15, 22-40.

Chittka L., Schürkens S. (2001) Successful invasion of a floral market. Nature, 411, 653.

Collins B.G., Rebelo T. (1987) Pollination biology of the Proteaceae in Australia and southern Africa. Australian Journal of Ecology, 12, 387-421.

Flanagan R.J., Mitchell R.J., Karron J.D. (2010) Increased relative abundance of an invasive competitor for pollination, Lythrum salicaria, reduces seed number in Mimulus ringens. Oecologia, 164, 445454.

Geerts S. (2011) Assembly and disassembly of bird pollination communities at the Cape of Africa (Doctoral dissertation, Stellenbosch University, Stellenbosch, South Africa).

Geerts S. (2016) Can short-billed nectar thieving sunbirds replace long-billed sunbird pollinators in transformed landscapes? Plant Biology, 18, 10481052.

Geerts S., Coetzee A., Rebelo T., Pauw A. (2020) Pollination structures plant and nectar-feeding bird communities in Cape fynbos, South Africa: implications for the conservation of plant-bird mutualisms. Ecological Research, 35, 838-856.

Geerts S., Malherbe S.D., Pauw A. (2012) Reduced flower visitation by nectar-feeding birds in response to fire in Cape fynbos vegetation, South Africa. Journal of Ornithology, 153, 297-301.

Geerts S., Moodley D., Gaertner M., Le Roux J.J., McGeoch M.A., Muofhe C., Richardson D.M., Wilson J.R. (2013) The absence of fire can cause a lag phase: the invasion dynamics of Banksia ericifolia (Proteaceae). Austral Ecology, 38, 931-941.

Geerts S., Pauw A. (2009) African sunbirds hover to pollinate an invasive hummingbird-pollinated plant. Oikos, 118, 573-579.

Geerts S., Pauw A. (2011a) Easy technique for assessing pollination rates in the genus Erica reveals road impact on bird pollination in the Cape fynbos, South Africa. Austral Ecology, 36, 656-662.

Geerts S., Pauw A. (2011b) Farming with native bees (Apis mellifera subsp. capensis Esch.) has varied effects on nectar-feeding bird communities in South African fynbos vegetation. Population Ecology, 53, 333-339.

George A.D. (1981) The genus Banksia L.f. (Proteaceae). Nuytsia, 3, 239-473.

George A.S. (1999) Banksia. In: Orchard A.E., Thompson H.S., McCarthy P.M. (Eds), Flora of Australia: Proteaceae 3: Hakea to Dryandra. Canberra, ACT,
Australia: Australian Biological Resources Study, CSIRO Publishing, (p. 416).

Gibson M.R., Pauw A., Richardson D.M. (2013)

Decreased insect visitation to a native species caused by an invasive tree in the Cape Floristic Region. Biological Conservation, 157, 196-203.

Gibson M.R., Richardson D.M., Pauw A. (2012) Can floral traits predict an invasive plant's impact on native plant-pollinator communities? Journal of Ecology, 100, 1216-1223.

Gray E.R., Van Heezik Y. (2016) Exotic trees can sustain native birds in urban woodlands. Urban Ecosystems, 19, 315-329.

Honig M.A., Cowling R.M., Richardson D.M. (1992) The invasive potential of Australian banksias in South African fynbos: a comparison of the reproductive potential of Banksia ericifolia and Leucadendron laureolum. Australian Journal of Botany, 17, 305314.

Jakobsson A., Padrón B., Traveset A. (2009) Competition for pollinators between invasive and native plants: effects of spatial scale of investigation (note). Ecoscience, 16, 138-141.

Kalinganire A., Harwood C.E., Slee M.U., Simons A.J. (2001) Pollination and fruit-set of Grevillea robusta in western Kenya. Austral Ecology, 26, 637-648.

Kandori I., Hirao T., Matsunaga S., Kurosaki T. (2009) An invasive dandelion unilaterally reduces the reproduction of a native congener through competition for pollination. Oecologia, 159, 559-569.

Kearns C.A., Inouye D.W. (1993) Techniques for pollination biologists. Boulder, CO, USA: University Press of Colorado.

Kearns C.A., Inouye D.W., Waser N.M. (1998) Endangered mutualisms: the conservation of plant-pollinator interactions. Annual Review of Ecology and Systematics, 29, 83-112.

Le Roux J.J., Clusella-Trullas S., Mokotjomela T.M., Mairal M., Richardson D.M., Skein L., Wilson J.R., Weyl O.L.F., Geerts S. (2020) Biotic interactions as mediators of biological invasions: Insights from South Africa. In: van Wilgen B., Measey J., Richardson D.M., Wilson J.R., Zengeya T.A. (Eds), Biological invasions in South Africa. Cham, Switzerland: Springer, pp. 387-427.

Le Roux J.J., Geerts S., Ivey P., Krauss S., Richardson D.M., Suda J., Wilson J.R.U. (2010) Molecular systematics and ecology of invasive Kangaroo Paws in South Africa: management implications for a horticulturally important genus. Biological Invasions, 12, 3989-4002.

Lundgren R., Lázaro A., Totland O. (2013) Experimental pollinator decline affects plant reproduction and is mediated by plant mating system. Journal of Pollination Ecology, 11, 46-56.

Mackay B., Lee A.T.K., Barnard P., Moller A.P., Brown M. (2017) Urbanization, climate and ecological stress indicators in an endemic nectarivore, the Cape Sugarbird. Journal of Ornithology, 158, 1013-1024.

Mangachena J.R., Geerts S. (2017) Invasive alien trees reduce bird species richness and abundance of mutualistic frugivores and nectarivores: a bird's eye view on a conflict of interest species in riparian habitats. Ecological Research, 32, 667-676.

Maruyama P.K., Vizentin-Bugoni J., Sonne J., Martín González A.M., Schleuning M., Araujo A.C., Baquero A.C., Cardona J., Cardona P., Cotton P.A., Kohler G., Lara C., Malucelli T., Marín-Gómez O.H., Ollerton J., Rui A.M., Timmermann A., Varassin I.G., Zanata T.B., Rahbek C., Sazima M., Dalsgaard B.O. (2016)
The integration of alien plants in mutualistic plant-hummingbird networks across the Americas: the importance of species traits and insularity. Diversity and Distributions, 22, 672-681.

Moodley D., Geerts S., Rebelo T., Richardson D.M., Wilson J.R. (2014) Site-specific conditions influence plant naturalization: the case of alien Proteaceae in South Africa. Acta Oecologia, 59, 62-71.

Moodley D., Geerts S., Richardson D.M., Wilson J.R. (2013) Different traits determine introduction, naturalization and invasion success in woody plants: Proteaceae as a test case. PLoS One, 8, e75078.

Moodley D., Geerts S., Richardson D.M., Wilson J.R. (2016) The importance of pollinators and autonomous self-fertilisation in the early stages of plant invasions: Banksia and Hakea (Proteaceae) as case studies. Plant Biology, 18, 124-131.

Morales C.L., Aizen M.A. (2006) Invasive mutualisms and the structure of plant-pollinator interactions in the temperate forests of north-west Patagonia, Argentina. Journal of Ecology, 94, 171-180.

Morales C.L., Traveset A. (2009) A meta-analysis of impacts of alien vs. native plants on pollinator visitation and reproductive success of co-flowering native plants. Ecology Letters, 12, 716-728.

Moroń D., Lenda M., Skórka P., Szentgyörgyi H., Settele J., Woyciechowski M. (2009) Wild pollinator communities are negatively affected by invasion of alien goldenrods in grassland landscapes. Biological Conservation, 142, 1322-1332.

Mostert D.P., Siegfried W.R., Louw G.N. (1980) Protea nectar and satellite fauna in relation to the food requirements and pollinating role of the Cape Sugarbird. South African Journal of Science, 76, 409-412.

Muñoz A.A., Cavieres L.A. (2008) The presence of a showy invasive plant disrupts pollinator service and reproductive output in native alpine species only at high densities. Journal of Ecology, 96, 459-467.

Nocentini D., Pacini E., Guarnieri M., Martelli D., Nepi M. (2013) Intrapopulation heterogeneity in floral nectar attributes and foraging insects of an ecotonal Mediterranean species. Plant Ecology, 214, 799-809.

Nottebrock H., Schmid B., Mayer K., Devaux C., Esler K.J., Böhning-Gaese K., Schleuning M., Pagel J., Schurr F.M. (2017) Sugar landscapes and pollinatormediated interactions in plant communities. Ecography, 40, 1129-1138.

Olesen J.M., Eskildsen L.I., Venkatasamy S. (2002) Invasion of pollination networks on oceanic islands: importance of invader complexes and endemic super generalists. Diversity and Distribution, 8, 181-192.

Ollerton J., Watts S., Connerty S., Lock J., Parker L., Wilson I., Schueller S.K., Nattero J., Cocucci A.A., Izhaki I., Geerts S., Stout J.C. (2012) Pollination ecology of the invasive tree tobacco Nicotiana glauca: Comparisons across native and non-native ranges. Journal of Pollination Ecology, 9, 85-95.

Ollerton J., Winfree R., Tarrant S. (2011) How many flowering plants are pollinated by animals? Oikos, 120, 321-326.

Parra-Tabla V., Angulo-Pérez D., Albor C., CamposNavarrete M.J., Tun-Garrido J., Sosenski P., Alonso C., Ashman T., Arceo-Gómez G. (2019) The role of alien species on plant-floral visitor network structure in invaded communities. PLoS One, 14, e0218227.

Paton D.C., Turner V. (1985) Pollination of Banksia ericifolia Smith: birds, mammals and insects as pollen vectors. Australian Journal of Botany, 33, 271-286. 
Pimentel D., Zuniga R., Morrison D. (2005) Update on the environmental and economic costs associated with alien-invasive species in the United States. Ecology Economics, 52, 273-288.

Prasifka J.R., Mallinger R.E., Portlas Z.M., Hulke B.S., Fugate K.K., Paradis T., Hampton M.E., Carter C.J. (2018) Using nectar-related traits to enhance croppollinator interactions. Frontier in Plant Science, 9, 812.

Pyšek P., Jarošík V., Chytrý M., Danihelka J.Í., Kühn I., Pergl J., Tichy L., Biesmeijer J.C., Ellis W.N., Kunin W.E., Settele J. (2011) Successful invaders co-opt pollinators of native flora and accumulate insect pollinators with increasing residence time. Ecological Monographs, 81, 277-293.

R Core Team. (2017) R: A language and environment for statistical computing. Vienna, Austria: R Foundation for Statistical Computing.

Rambuda T.D., Johnson S.D. (2004) Breeding systems of invasive alien plants in South Africa: does Baker's rule apply? Diversity and Distribution, 10, 409-416.

Razanajatovo M., Maurel N., Dawson W., Essl F., Kreft H., Pergl J., Pyšek P., Weigelt P., Winter M., Van Kleunen M. (2016) Plants capable of selfing are more likely to become naturalized. Nature Communications, 7, 1-9.

Rebelo T. (2001) SASOL Proteas: a field guide to the Proteas of Southern Africa. Caped Town, South Africa: Fernwood Press.

Richards M.B., Cowling R.M., Stock W.D. (1995) Fynbos plant communities and vegetation-environment relationships in the Soetanysberg hills, Western Cape. South African Journal of Botany, 61, 298-305.

Richardson D.M., Allsopp N., D’Antonio C.M., Milton S.J., Rejmánek M. (2000) Plant invasions - The role of mutualisms. Biological Reviews, 75, 65-93.

Richardson D., Cowling R.M., Le Maitre D.C. (1990) Assessing the risk of invasive success in Pinus and Banksia in South African mountain fynbos. Journal of Vegetation Science, 1, 629-642.

Rodger J.G., Van Kleunen M., Johnson S.D. (2010) Does specialized pollination impede plant invasions? International Journal of Plant Sciences, 171, 382-391.

Rourke J.P. (1982) The proteas of Southern Africa. London, UK: Centaur, p. 240.

Schmid B., Nottebrock H., Esler K.J., Pagel J., Pauw A., Böhning-Gaese K., Schurr F.M., Schleuning M. (2015) Reward quality predicts effects of birdpollinators on the reproduction of African Protea shrubs. Perspectives in Plant Ecology, Evolution and Systematics, 17, 209-217.

Schmid B., Nottebrock H., Esler K.J., Pagel J., Pauw A., Böhning-Gaese K., Schurr F.M., Schleuning M. (2016) Responses of nectar-feeding birds to floral resources at multiple spatial scales. Ecography, 39, 619-629.

Steenhuisen S.L., Johnson S.D. (2012) Evidence for autonomous selfing in grassland Protea species (Proteaceae). Botanical Journal of the Linnean Society, 169, 433-446.

Sun S.G., Huang Z.H., Chen Z.B., Huang S.Q. (2017) Nectar properties and the role of sunbirds as pollinators of the golden-flowered tea (Camellia petelotii). American Journal of Botany, 104, 468476.

Traveset A., Richardson D.M. (2014) Mutualistic interactions and biological invasions. Annual Review of Ecology, Evolution, and Systematics, 45, 89-113.

Vamosi J.C., Knight T.M., Steets J.A., Mazer S.J., Burd M., Ashman T.L. (2006) Pollination decays in biodiversity hotspots. Proceedings of the National Academy of Sciences, USA, 103, 956-961.

Van Kleunen M., Dawson W., Schlaepfer D., Jeschke J.M., Fischer M. (2010) Are invaders different? A conceptual framework of comparative approaches for assessing determinants of invasiveness. Ecology Letters, 13, 947-958.

Van Wilgen B.W. (2009) The evolution of fire and invasive alien plant management practices in fynbos. South African Journal of Science, 105, 335-342.

Vilà M., Bartomeus I., Dietzsch A.C., Petanidou T., Steffan-Dewenter I., Stout J.C., Tscheulin T. (2009) Invasive plant integration into native plant-pollinator networks across Europe. Proceedings of the Royal Society, series B: Biological Sciences, 276, 3887-3893.

Vilà M., Espinar J.L., Hejda M., Hulme P.E., Jarošík V., Maron J.L., Pergl J., Schaffner U., Sun Y., Pyšek P. (2011) Ecological impacts of invasive alien plants: a meta-analysis of their effects on species, communities and ecosystems. Ecology Letters, 14, 702-708. 